Hammond, J., Jones, V., Hill, E.L., Green, D. \& Male, I. (2014). An investigation of the impact of regular use of the Wii Fit to improve motor and psychosocial outcomes in children with movement difficulties: A pilot study. Child Care Health Development, 40(2), 165-175. (Wiley)

DOI: $10.1111 /$ cch.12029

\title{
An investigation of the impact of regular use of the Wii Fit to improve motor and psychosocial outcomes in children with movement difficulties: A pilot study
}

\author{
James Hammond ${ }^{1}$, Victoria Jones ${ }^{1}$, Elisabeth Hill2*, Dido Green ${ }^{3} \&$ Ian Male $^{4}$
}

1. Brighton \& Sussex Medical School, University of Sussex.

2. Elisabeth Hill, PhD. Professor of Neurodevelopmental Disorders, Department of Psychology, Goldsmiths, University of London, New Cross, London, SE14 6NW. Email: e.hill@gold.ac.uk

3. Dido Green, PhD. Reader in Rehabilitation, Centre for Rehabilitation, Oxford Brookes University.

4. Ian Male, MB.BCh, MRCP, MSc. Consultant Community Paediatrician. Mid Sussex Child Development Centre.

* Corresponding author

Conflict of interest: No authors have any conflict of interest with respect to this work.

Short title: Therapeutic use of the Wii Fit for children.

Keywords: DCD, fitness, intervention, motor skill

\section{Acknowledgements}

We are grateful to the schools, parents and children who participated in this study, particularly to Mrs Katherine Jackson at Northlands Wood School, Haywards Heath and Ms Kit Messenger at Manor Field School, Burgess Hill, Sussex, UK. This project received funding from Brighton and Sussex Medical School as a medical student study.

\begin{abstract}
Background: Children with DCD experience poor motor and psychosocial outcomes. Interventions are often limited within the health care system, and little is known about how technology might be used within schools or homes to promote the motor skills and/or psychosocial development of these children. This study aimed to evaluate whether short, regular school-based sessions of movement experience using a commercially available home video game console (Nintendo's Wii Fit) would lead to benefits in both motor and psychosocial domains in children with DCD.

Methods: A randomised cross-over controlled trial of children with movement difficulties/DCD was conducted. Children were randomly assigned to an intervention $(n=10)$ or comparison $(\mathrm{n}=8)$ group. The intervention group spent ten minutes thrice weekly for one month using Wii Fit during the lunch break, while the comparison group took part in their regular Jump Ahead programme. Pre- and post-intervention assessments considered motor proficiency, self-perceived ability and satisfaction and parental assessment of emotional and behavioural problems.

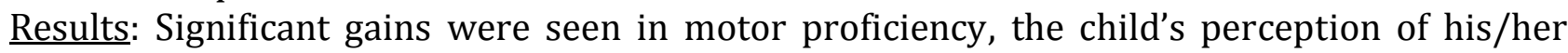
motor ability and reported emotional well-being for many, but not all children.

Conclusions: This study provides preliminary evidence to support the use of the Wii Fit within therapeutic programmes for children with movement difficulties. This simple, popular intervention represents a plausible method to support children's motor and psychosocial development. It is not possible from our data to say which children are most likely to benefit
\end{abstract}


from such a programme and particularly what the dose and duration should be. Further research is required to inform across these and other questions regarding the implementation of virtual reality technologies in therapeutic services for children with movement difficulties.

\section{Introduction}

Developmental Coordination Disorder is a common neurodevelopmental disorder, affecting 1.8 to $4 \%$ of school aged children (Lingam et al., 2009); characterised by a marked impairment in the development of motor coordination (American Psychiatric Association, 2000). Affected children may experience difficulties in the planning, organisation and/or execution of movements resulting in delays in the acquisition of fine and gross motor skills (Henderson \& Henderson, 2001). Consequently children may encounter problems with a range of motor tasks such as running, dressing and writing (Dewey \& Wilson 2001; Leeds Consensus Statement, 2006). Difficulties in these skills can make it harder to join in socially, for example in team sports (Poulsen et al., 2008a), or to fulfil potential in school where an inability to record information quickly and neatly can be mistaken for laziness or low academic ability. This often leads to harmful secondary consequences such as poor academic achievement, low self-esteem (Cairney et al., 2005a; Lingam et al., 2010; Piek et al., 2006; Poulsen et al., 2008a; 2008b), reduced physical activity participation (Green et al., 2011) and obesity (Cairney et al., 2005b).

The impact of poor motor coordination may be felt across all aspects of a child's life, whether at school, home, in play or friendships (e.g., Poulsen et al., 2008a; Malloy-Miller et al., 1995). Indeed, parents consistently report that coordination difficulties have a significant effect on their child's quality of life (Pless et al., 2001; Segal et al., 2002; Stephenson \& Chesson, 2008).

Although children with DCD may acquire new motor skills over time, there is growing evidence that they do not 'outgrow' their motor difficulties and require intervention to improve (Cantell et al., 2003; Kirby et al., 2008). One follow-up study which tested motor proficiency in children aged six showed that they still experienced similar levels of motor difficulty when aged sixteen, and the consequences of these problems persist into adulthood (Hellgren et al., 1993; Rasmussen \& Gillberg, 2000). Cross-sectional studies of adults show significant consequences of both motor skill and quality of life satisfaction (Cousins \& Smyth, 2003; Hill et al. 2011). Such studies highlight the importance of suitable support and intervention in childhood. Despite these poor outcomes, parents often report considerable difficulty accessing diagnosis or treatment for their child and may see many professionals before receiving support (Dunford \& Richards, 2003; Green et al., 2005; Segal et al., 2002).

Even where treatment is available there is conflicting evidence and opinion as to the best interventions for DCD (Leeds Consensus Statement, 2006; Mandich et al., 2001; Wilson, 2005). Some interventions take a task-oriented approach aiming to improve the child's performance at specific day-to-day motor tasks (Pless et al., 2000; Jongmans et al., 2003). Given the wide array of motor domains affected by DCD, and its high prevalence, the focus on developing specific tasks may place significant strain on professional resources. Deficit orientated approaches, based on theories that motor deficits are the result of abnormal development (Wilson \& McKenzie, 1998; Wilson, 2005), aim to train specific neuropsychological functions believed to be responsible for motor functioning and therefore contribute to more global improvements in motor skills. One local school based programme, 'Jump Ahead', targets the hypothesised sensory-perceptual deficits and is aimed at children with special educational needs.

Recent research suggests that the use of virtual reality systems may be beneficial as an intervention tool for motor deficits in a variety of conditions, particularly the rehabilitation of stroke, acquired brain injury and cerebral palsy (Golomb et al., 2010; Green \& Wilson, 2012; Lucca, 2009; Mumford \& Wilson, 2009; Sandlund et al., 2008; Snider et al., 2010; Weiss et al., 2004). Virtual reality utilises interactive simulations created with computer hardware and 
software, providing opportunities to interact and manipulate virtual objects in real-time, in a multidimensional and multisensory virtual environment (Pridmore et al., 2007).

Virtual reality therefore has many properties which makes it a desirable interventional tool for motor difficulties. It provides users with opportunities to perform tasks they may not be able to execute in the 'real-world' offering experimental, active learning in a safe and controlled environment (Green \& Wilson, 2012). By allowing interaction with displayed images and manipulation of virtual objects, users see how their movements in the 'real-world' affect the 'virtual world' enhancing awareness of their movements. Overall, interventions using technology have been shown to have many advantages including continued motivation, positive behaviour and higher success rates (Green \& Wilson 2011). However, these systems are not widely available outside of research settings, are often very expensive and require training to use. The Nintendo Wii is a commercially available, low-cost virtual reality gaming console which uses motion sensors (www.nintendo.co.uk). The Wii fit uses a remote balance board as the input into the virtual environment. The board contains sensors which measure user's motions and maps then onto the virtual environment. It uses differences in the applied forces and movements to change the amount of visual and audio feedback it provides. Casestudy reports, as well as randomised trials, have suggested the Nintendo Wii Fit to be useful in enhancing motor proficiency in stroke patients (Mouawad et al., 2011; Saposnik et al., 2010) and a child with diplegic cerebral palsy (Deutsch et al., 2008); however data are very limited (Laver et al., 2011).

The Wii and Wii Fit have the potential, as an affordable intervention, to improve movement skills and increase participation in physical activity for a large number of children. A pilot project was therefore developed to determine whether a short term (three times a week over a month) programme, delivered in school using the basic balance games which come with the Wii Fit, could improve motor proficiency. Secondary aims explored any benefits this may give to self perception of motor ability and reports of psycho-social development.

\section{Methodology \\ Participants}

Participants were recruited from two primary schools in Mid-Sussex, UK following a two stage recruitment process as recommended by Wright and Sugden (1996; see Figure 1). In the first stage, senior members of staff at each school identified children who were judged to be at risk of functional movement problems. These children were taking part in 'Jump-Ahead', a local school-run motor intervention programme for children with movement difficulties, including some with a formal diagnosis of DCD. Additional inclusion criteria required children to have normal IQ (based on school assessments) and no evidence of a medical/neurological disorder making participation inappropriate, such as photosensitive epilepsy. As this was a pilot project no screening for common comorbidities of movement impairments (e.g., attention deficit, dyslexia, peer problems. were undertaken. Fifty two children from a total school population of 450 were identified at this stage.

At this point, each child's teacher completed the Developmental Coordination Disorder Questionnaire (DCDQ; Wilson et al., 2007). The DCDQ is a screening questionnaire made up of 15 items assessing children's motor performance in everyday activities. This questionnaire is considered a valid clinical screening tool for children who have coordination difficulties (Wilson et al., 2009). Children were included in the study if they were considered to be at risk of movement difficulties (scoring within the bottom quintile on the DCDQ) and/or had a diagnosis of DCD. On this basis, a total of 20 children were invited to take part in the intervention study, and parental consent was then obtained. Confirmation of a risk of movement difficulties was then undertaken using a standardised motor test (see below). A slightly higher cut-off than the typical $5^{\text {th }}$ or $15^{\text {th }}$ percentile used for consideration of a diagnosis of DCD was considered important due to the ethnographic elements of this study 
(school-based) and taking into consideration differences between standardised assessments and their relevant cut-off points (Venetsanou et al., 2011). Children were aged 7-10 years to allow for experiential differences in the pre-school/early school years prior to transfer to secondary education. Participant characteristics are shown in Table.1. Ethics approval for the study was granted by Brighton West Research Ethics Committee and the Sussex NHS Research Consortium.

\section{Intervention}

This was a cross-over intervention study with two phases, each lasting four weeks. In Phase.1 children were divided randomly into two groups: Group.A $(n=10)$ received ten minutes of supervised play on Wii Fit three times a week (hitherto, Wii Fit intervention). Children had a choice of nine Wii Fit games which focus on balance and coordination. Children were withdrawn from other interventions for this four week period. Group. $B(n=8)$ continued in the 'treatment as usual' school-run Jump Ahead intervention (1 hour per week) (hitherto, Control period). In this programme, children with a range of difficulties work in groups practicing motor skills (see http://wsgfl.westsussex.gov.uk/ccm/navigat...id=aMaqoL5ixUDg). Phase.2 commenced 2.5 months after the end of Phase.1. During Phase.2 the groups participated in the alternative intervention for the following four weeks. Timing of the Wii sessions was at the discretion of the schools, during lunch-time and under the supervision of one of the researchers or one member of the teaching staff.

\section{Measures}

Children's motor skills, self-perceived ability and satisfaction with motor tasks as well as parental assessment of social behaviour and psychopathology were assessed at each of three time points: baseline (week 0), after Phase.1 (end of week 4) and after Phase.2 (end of week 18).

Motor proficiency (child): The short form of the Bruininks-Oseretsky Test (2nd edition; BOT-2) (Bruininks \& Bruininks, 2005) was completed for each child. This assesses fine manual control, manual coordination, body coordination, strength and agility and provides a single motor composite score. The test is normed for four-21 years of age and is a useful tool for motor assessment and development and evaluation of motor training programmes (Bruininks \& Bruininks, 2005).

Self-perceived ability and satisfaction with motor tasks (child): The Coordination Skills Questionnaire (CSQ; Green \& Wilson, 2008) is a ten-item questionnaire, modeled on the Canadian Occupational Performance Measure (Law et al., 1994), completed by a child. S/he ranks his/her perceived ability level and satisfaction in performance across a range of movement tasks using a five-point response scale that is matched to a semantic scale (range of 9-45 (the 10th item is not included in the overall score). Internal reliability and construct validity of this scale are good (Green, 2006).

Emotional and behavioural development (parent): The Strengths and Difficulties Questionnaire (SDQ; Goodman, 1997) is a 25-item parental report questionnaire that provides a brief measure of social behaviour and psychopathology with good reliability and validity reported.

\section{Statistical Procedures}

Descriptive and quantitative analyses were undertaken. Primary outcomes considered the effect of training on the Wii on motor skills. Secondary outcomes considered the impact of training on self-perception and behaviour. These were addressed through the use of a mixed 
ANOVA (between subject factor, intervention group; within subject factor, time; baseline, end Phase.1, end Phase.2) and post hoc analyses with Bonferroni corrections ${ }^{1}$. Calculation of the least degree of difference (LDD) ${ }^{2}$, representing a clinically meaningful degree of change was undertaken to determine the numbers of children making meaningful progress.

$<$ Table.1 \& Figure.1 about here>

\section{Results}

There were no differences in the baseline characteristics between the two groups (see Table.1). Individual children's data are shown in Table.2 ${ }^{3}$. From the initial SDQ scores, there was a trend for children in Group.A to have a greater degree of associated difficulties. In total, five children had abnormal scores; four in Group.A, one in Group.B; seven children had reported hyperactivity: six in Group.A, one in Group.B; two children had peer problems: both Group.B.

Both groups showed improved BOT-2 total scores following the Wii intervention period (see Figure.2; Group.A: baseline to end of Phase.1, Group.B: end of Phase.1 to end of Phase.2). A mixed ANOVA comparing the two intervention groups over time identified no significant main effects of either group $[F(1,15)=.00, p=.987]$ or time $[F(1.46,21.84)=2.73$, $\mathrm{p}=.082]$. The group $\mathrm{x}$ time interaction was significant $[\mathrm{F}(1.46,21.84)=6.27, \mathrm{p}<.02]$. Posthoc comparisons revealed that this interaction stems from a significant improvement in BOT-2 percentile in Group.A between baseline and end of Phase.1 ( $\mathrm{p}<.01)$, but no significant difference between comparison of other assessment times in this group, and no differences in any comparison for Group.B.

BOT-2 subscores showed improvement during the Wii Fit intervention period for each group (see Table.3). Three children made meaningful progress ( $\geq 1$ LDD change) during the Wii programme and one child nearly achieved this during the control period. Six children achieved $>1 / 2$ LDD during the Wii programme in comparison to two during the control period. During their respective control periods, seven children got worse (two in Group.B, five in Group.A but none reaching 1 LDD). Eight children moved out of the 'at risk' area for coordination difficulties ( $>20^{\text {th }}$ percentile) during their Wii fit programme in comparison to only one child who achieved this during their control period. See Table. 2 for comparisons.

\section{$<$ Tables.2-4 and Figure.2 about here $>$}

CSQ scores, reflecting the child's perception of their motor ability, improved in Group.A over the Wii Fit intervention period and remained unchanged over the ensuing control period. Group.B improved during the control period and continued to improve over the intervention period (see Figure 2 and Table 4). This improvement was not, however, significant in the analyses: For both the CSQ Ability and Satisfaction scores, a mixed ANOVA comparing the two intervention groups over time, revealed no significant main effects of group [Ability: $\mathrm{F}(1,16)=.22, \mathrm{p}=.649$; Satisfaction: $\mathrm{F}(1,16)=.33, \mathrm{p}=.577$ ] and no group $\mathrm{x}$ time interactions

\footnotetext{
${ }^{1}$ Descriptive analyses were conducted to look at distribution of scores. Where violations of normality were observed, non-parametric analyses were conducted, with the same results.

${ }^{2} \operatorname{LDD}(1.9 * \sqrt{ } 2 * \mathrm{SEM})$ averaged 10.7 standard score points for BOT-2 across ages.

3 Overall BOT-2 score for one child in Group.B is above our cut-off at baseline. However, he had a variable profile with significant difficulties in particular subtests, and considerable functional movement difficulties as evidenced by a very low score on the DCDQ. Analyses were run with and without this child included. Results were unaffected and he was therefore retained in the group.
} 
[Ability: $F(1.489,23.827)=2.24, p=.139$; Satisfaction: $F(1,16)=1.43, p=.254$ ]. The main effect of time was significant [Ability: $F(1.489,23.827)=14.56, p<.001$; Satisfaction: $F(1,16)=11.36$, $\mathrm{p}<.001]$. In both cases, this effect arose from a significant increase in scores between baseline and end of Phase. 1 as well as between baseline and end of Phase.2 (all significant ps<.01). There was no change in scores between the end of Phases.1 and 2. More children rated their ability and satisfaction with their skills $>1$ LDD following participation in the Wii programme, particularly so for Group.A, who, for the most part, maintained these higher levels of selfperception during Phase.2.

Only seven parents completed SDQs at both study entry and at the end of Phase.1 (Group.A=4. Group.B=3). Mean total score and subscores all improved in Group.A following the Wii Fit intervention (one child moving from abnormal to borderline pathology risk and one from borderline to normal), while they remained unchanged in Group.B after the Jump Ahead sessions (the small sample precludes further analysis). There was no difference in improvements in motor ability in children with/without elevated SDQ scores.

\section{Discussion}

This small pilot study provides encouraging results as to the potential for the Wii Fit programme to engender change in motor skills and related social and emotional behaviours. In view of the small sample size, the results need to be treated with caution. However they provide interesting points warranting further discussion, particularly in view of the fact that many children have access to the Nintendo Wii and may be using this system at home with minimal supervision.

These findings suggest that using the Wii Fit balance games for ten minutes, three times a week in a school setting over a one month period may lead to gains in motor proficiency (BOT-2 scores), the child's perception of his/her motor ability (CSQ) and the child's emotional well-being (SDQ) for many, but not all children. The greatest (significant) gains were seen in gross motor proficiency, which may be predictable given that the games focus on balance skills and bilateral coordination, and less so in fine motor precision and visuo-motor integration. It is encouraging, though, that gains were also seen in these skills, suggesting that the games help develop broader motor coordination skills, not just those related to balance but also those needed to play at and improve in game performance. Whilst the fall in motor proficiency scores for Group.A over the control period suggests that the gains of the intervention period were not sustained after intervention ceased, it is encouraging that children's perception of improved ability continued. Given long term concerns over selfesteem, and the difficulties many of these children encounter in joining in with physical activity with their peers, this continued positive perception may enhance long term outcome. Changes in a child's perception of his/her motor ability over time, but not as a function of either intervention, may reflect natural (developmental) change, or other factors. The significance of reported changes in psychosocial development, with such small numbers, is difficult to interpret, although the improvements are a promising avenue for future research. The duration of the programme, whilst sufficient to elicit short term gains across a number of measures, may not have been enough to support consolidation over a longer term as reflected by the regression of performance on the BOT-2 of Group.A during Phase.2.

As an intervention, playing on the Wii Fit was popular with school staff and children (who showed willing and excellent attendance) which is consistent with evidence supporting the use of virtual reality (VR) technologies for leisure and play (Reid, 2004; Weiss et al., 2003). The Wii is relatively cheap, particularly in comparison to other VR technologies, and is easy to set up and run in a school environment, especially where interactive whiteboards are available. Furthermore, therapeutic sessions were easily supervised by teaching assistants.

With a small pilot study, limitations are clear. While recruitment was dependent on selection of children perceived as having movement difficulties by their teachers, subsequent assessment ensured that children showed signs of movement difficulties. In addition, the lack 
of blinding of the researchers and the extended period between the end of Phase. 1 and beginning of Phase.2, may have influenced the results. However, to some extent, the crossover design mediates against this limitation, as any bias would have influenced both groups equally, and goes some way to providing a solid base from which to interpret the results showing that despite the pilot's limitations there is a clear, relative benefit of the Wii intervention. Furthermore, with only a case report successfully using the Wii in a single child with cerebral palsy (Deutsch et al., 2008) and a few studies of stroke "Wiihabilitation" (Mouawad et al., 2011; Saposnik et al., 2010; Laver et al., 2011), the results of this study are encouraging in providing preliminary evidence for its therapeutic use. Considering the pressures on clinical services with excessive waiting times for receipt of limited therapies, utilising such technologies for therapeutic purposes offers a positive alternative to address the needs of a large number of children. For this purpose it will be important to explore which games and technologies work best to exploit particular gains for specific children (and ages) including physical activity and fitness and in which contexts of application (e.g., home, school, community facilities). Important questions regarding dose, intensity and duration of treatments remain outstanding for both the Wii fit programme (10 minute 3 times a week, 30 minutes total) as well as the 'treatment as usual' (1 hour once a week). Our small sample size prevents analysis of equally important questions regarding which children are most likely to benefit from such a programme including those with additional diagnoses known to commonly co-occur with DCD (Green \& Baird, 2005; Hill, 2001; Lingam et al. 2010). It is encouraging that the children with co-existing hyperactivity and/or peer problems showed improvements in their motor ability following their intervention phase. Thus there is a clear need for larger blinded, randomised, controlled studies to investigate the benefits of using a Wii programme for children with coordination difficulties.

\section{Conclusion}

This study provides preliminary evidence to support the use of the Wii Fit within therapeutic programmes for children with movement difficulties. It is not possible from our data, and the limited number of participants, to say which children are most likely to benefit from such a programme and particularly what the dose and duration should be. Further research is required to inform across these and other questions regarding the implementation of VR technologies in therapeutic services for children with movement difficulties.

\section{Key messages}

- DCD is a common disability with risk of persistent difficulties into adulthood influencing psychosocial as well as medical outcomes.

- Access to effective therapies is often limited.

- This study provides evidence for use of the Wii Fit as an affordable and accessible intervention influencing motor as well as psychosocial outcomes for many children with movement difficulties.

- Further studies are required to identify who is most likely to benefit from such a programme and particularly what the dose and duration should be.

\section{References}

American Psychiatric Association. (2000) Diagnostic and Statistical Manual of Mental Disorders, Fourth Edition (text revision). American Psychiatric Association, Washington, DC. American Psychiatric Association.

Bruininks RH, Bruininks BD. (2005) Bruininks-Oseretsky Test of Motor Proficiency, Second Edition. Pearson Inc., London. 
Coordination Disorder, generalised self-efficacy toward physical activity, and participation in organised and free play activities. Journal of Pediatrics, 147, 515-520.

Cairney, J., Hay, J.A., Faught, B.E. \& Hawes, R. (2005b) Developmental coordination disorder and overweight and obesity in children aged 9-14y. International Journal of Obesity, 29, 369372 .

Cantell, M.H., Smyth, M.M. \& Ahonen, T.P. (2003) Two distinct pathways for developmental coordination disorder: persistence and resolution. Human Movement Science, 22, 413-431.

Cousins, M. \& Smyth, M.M. (2003) Developmental coordination impairments in adulthood. Human Movement Science, 22, 433-459.

Deutsch, J. E., Borbely, M., Filler, J., Huhn, K. \& Guarrera-Bowlby, P. (2008) Use of a low-cost, commercially available gaming console (Wii) for rehabilitation of an adolescent with cerebral palsy. Physical Therapy, 88, 1196-1207.

Dewey, D. \& Wilson, B.N. (2001) Developmental coordination disorder: what is it? Physical and Occupational Therapy in Pediatrics, 20, 5-27.

Dunford, C. \& Richards, S. (2003) Doubly Disadvantaged' Report of a survey on waiting lists and waiting times for children with Developmental Coordination Disorder. College of Occupational Therapists, London, UK.

Golomb, M.R., McDonald, B.L., Warden, S.J., Yonkman, J., Saykin, A.J., Shirley, B., Huber, M., Rabin, B., AbdelBaky, M., Nwosu, M., Barkat-Masih, M. \& Burdea, G.C. (2010) In-home VR videogame telerehabilitation in adolescents with hemiplegic cerebral palsy. Archives Physical Medicine Rehabilitation, 91, e1-8.

Goodman, R. (1997) Strengths and Difficulties Questionnaire: a research note. Journal of Child Psychology \& Psychiatry, 38, 581-585.

Green, D. (2006). A qualitative and quantitative study of the nature of Developmental Coordination Disorder. Unpublished doctoral dissertation, University of Leeds, UK.

Green, D., \& Baird, G. (2005). DCD and overlapping conditions. In D. Sugden \& M. M. Chambers (Eds.), Children with developmental coordination disorder (pp. 93-118). London: Whurr.

Green, D. Bishop, T., Wilson B., Crawford, S., Hooper, R., Kaplan, B. \& Baird, G. (2005) Is questionnaire-based screening part of the solution to waiting lists for children with Developmental Coordination Disorder? British Journal of Occupational Therapy, 68, 2-10.

Green, D., Lingam, R., Mattocks, C., Riddoch, C., Ness, A. \& Emond, A. (2011). The risk of reduced physical activity in children with probable Developmental Coordination Disorder: a prospective longitudinal study. Research in Developmental Disabilities, 34, 1332-1342.

Green, D. \& Wilson, B.N. (2008) Value of Parent and Child Opinion in Detecting Change in Movement Capabilities. Canadian Journal of Occupational Therapy. 75, 208-219.

Green, D. \& Wilson, P.H. (2012) Use of virtual reality in rehabilitation of movement in children with hemiplegia - A multiple case study evaluation. Disability\& Rehabilitation, 34, 593-604. 
Hellgren, L., Gillberg, C., Gillberg, I.C. \& Enerskog, E. (1993) Children with deficits in attention, motor control and perception (DAMP) almost grown up; General health at 16 years. Developmental Medicine \& Child Neurology, 35, 881-893.

Henderson, S.E. \& Henderson, L. (2003) Towards an understanding of Developmental Coordination Disorder: Terminological and Diagnostic Issues, Neural Plasticity, 10, 1-13.

Hill, E.L. (2001). The nonspecific nature of specific language impairment: a review of the literature with regard to concomitant motor impairments. International Journal of Language and Communication Disorders, 36, 149-171.

Hill, E.L., Brown, D. \& Sorgardt, K. S. (2011) A preliminary investigation of quality of life satisfaction reports in emerging adults with and without developmental coordination disorder. Journal of Adult Development, 18, 130-134.

Jongmans, M.J., Linthorst-Bakker, E., Westenberg, Y. \& Smits-Engelsman, B.C.M. (2003) Use of a task-oriented self-instruction method to support children in primary school with poor handwriting quality and speed. Human Movement Science, 22, 549-566.

Kirby, A., Sugden, D., Beveridge, S. \& Edwards, L. (2008) Developmental Co-ordination Disorder (DCD) in adolescents and adults in further and higher education. Journal of Research in Special Education Needs, 8, 120-131.

Laver, K. E., George, S., Thomas, S., Deutsch, J. E. \& Crotty, M. (2011) Virtual reality for stroke rehabilitation. Cochrane Database of Systematic Reviews, 7,9:CD008349.

Law, M., Polatajko, H., Pollock, N., McColl, M.A., Carswell, A. \& Baptiste, S. (1994). Pilot testing of the Canadian Occupational Performance Measure: clinical and measurement issues.

Canadian Journal of Occupational Therapy, 61, 191-197.

Leeds Consensus Statement. (2006) Leeds Consensus Statement: Developmental Coordination Disorder as a Specific Learning Difficulty. University of Leeds, Leeds, UK.

Lingam, R., Hunt, L., Golding, J., Jongmans, M. \& Emond, A. (2009) Prevalence of Developmental Coordination Disorder using the DSM-IV at 7 years of age: A UK population-based study. Pediatrics, 123, e693-e700.

Lingam, R., Golding, J., Jongmans, M.J., Hung, L.P., Ellis, M. \& Emond, A. (2010) The association between Developmental Coordination Disorder and other developmental traits. Pediatrics, 126, e1109-e1118.

Lucca, L.F. (2009) Virtual reality and motor rehabilitation of the upper limb after stroke: a generation of progress? Journal of Rehabilitation Medicine, 41, 1003-1006.

Malloy-Miller, T., Polatajko, H. \& Anstett, B. (1995) Handwriting error patterns of children with mild motor difficulties. Canadian Journal of Occupational Therapy, 62, 258-267.

Mandich, A., Polatajko, H.J., Macnab, J.J. \& Miller, L.T. (2001) Treatment of children with developmental coordination disorder: What is the evidence: Physical \& Occupational Therapy in Pediatrics, 20, 51-68.

Mouawad, M. R., Doust, C. G., Max, M. D. \& McNulty, P. A. (2011) Wii-based movement therapy to 
promote improved upper extremity function post-stroke: a pilot study. Journal of Rehabilitation Medicine, 43, 527-533.

Mumford, N. \& Wilson, P.H. (2009) Virtual reality in acquired brain injury upper limb rehabilitation: Evidence-based evaluation of clinical research. Brain Injury, 23, 179-191.

Piek, J.P., Baynam, G.B. \& Barrett, N.C. (2006) The relationship between fine and gross motor ability, self-perceptions and self-worth in children and adolescents. Human Movement Science, 25, 65-75.

Pless, M. \& Carlsson, M. (2000) Effects of Motor Skill Intervention on Developmental Coordination Disorder: A Meta-Analysis. Adapted Physical Activity Quarterly, 17, 381-401.

Pless, M., Persson, K., Sundelin, C. \& Carlsson, M. (2001) Children with developmental coordination disorder: a qualitative study of parents' descriptions in M. Pless (2001) Developmental co-ordination disorder in pre-school children. Effects of motor skill intervention, parents' descriptions, and short-term follow-up of motor status. Acta Universitatis Upsaliensis, Uppsala, SE.

Poulsen, A. A., Ziviani, J. M., Johnson, H. \& Cuskelly, M. (2008a) Loneliness and life satisfaction of boys with developmental coordination disorder: the impact of leisure participation and perceived freedom in leisure. Human Movement Science, 27, 325-343.

Poulsen, A.A., Ziviani, J.M. \& Cuskelly, M. (2008b) Leisure time physical activity energy expenditure in boys with developmental coordination disorder: the role of peer relations selfconcept perceptions. OTJR: Occupation, Participation and Health, 28, 1-11.

Pridmore, T., Cobb, S., Hilton, D., Green, J. \& Eastgate, R. (2007) Mixed reality environments in stroke rehabilitation: Interfaces across the real/virtual divide. International Journal of Disability \& Human Development, 6, 3-10.

Rasmussen, P. \& Gillberg, C. (2000) Natural outcome of ADHD with Developmental Coordination Disorder at Age 22 Years: A controlled, longitudinal, community-based study. Journal of the American Academy of Child \& Adolescent Psychiatry, 39, 1424-1431.

Reid, D. (2004) The influence of virtual reality on playfulness in children with cerebral palsy: A pilot study. Occupational Therapy International, 11, 131-144.

Sandlund, M., McDonough, S. \& Hager-Ross, C. (2011) Interactive computer play in rehabilitation of children with sensorimotor disorders: a systematic review. Developmental Medicine \& Child Neurology, DOI: 10.1111/j.1469-8749.2008.03184.x

Saposnik, G., Teasell, R., Mamdani, M., Hall, J., Mcllroy, W., Cheung, D., Thorpe, K.E., Cohen, L.G., Bayley, M. \& Stroke Outcome Research Canada (SORCan) Working Group (2010) Effectiveness of virtual reality using Wii gaming technology in stroke rehabilitation: a pilot randomized clinical trial and proof of principle. Stroke, 41, 1477-1484.

Segal, R., Mandich, A., Polatajko, H. \& Cook, J.V. (2002) Stigma and its management: A pilot study of parental perceptions of the experiences of children with Developmental Coordination Disorder. American Journal of Occupational Therapy, 56, 422-428.

Sims, K., Henderson, S.E., Hulme, C. \& Morton, J. (1996a) The remediation of clumsiness. I: an 
evaluation of Laszlo's kinaesthetic approach. Developmental Medicine and Child Neurology, 38, 967-987.

Snider, L., Majnemer, A. \& Darsaklis, V. (2010) Virtual reality as a therapeutic modality for children with cerebral palsy. Developmental Neurorehabilitation, 13, 120-128.

Stephenson, E.A. \& Chesson, R.A. (2008) 'Always the guiding hand': parents' accounts of the long-term implications of developmental coordination disorder for their children and families. Child: care, health and development, 34, 335-343.

Venetsanou, F., Kambas, A., Ellinoudis, T., Fatouros, I., Giannakidou, D. \& Kourtessis, T. (2011). Can the Movement Assessment Battery for Children-Test be the "gold standard" for the motor assessment of children with Developmental Coordination Disorder? Research in Developmental Disabilities, 32, 1-10.

Weiss, P.L., Bialik, P. \& Kizony, R. (2003) Virtual reality provides leisure time opportunities for young adults with physical and intellectual disabilities. Cyperpsychology Behavior, 6, 335-342.

Wilson, B.N., Kaplan, B.J., Crawford, S.G. \& Roberts, G. (2007) The Developmental Coordination Disorder Questionnaire-2007 (DCDQ'07), Alberta Children's Hospital, Calgary, Canada.

Wilson, B.N., Crawford, S.G., Green, D., Roberts, G., Aylott, A. \& Kaplan, B.J. (2009) Psychometric Properties of the Revised Developmental Coordination Disorder Questionnaire, Physical \& Occupational Therapy in Pediatrics, 29, 182-202.

Wilson, P. (2005) Practitioner Review: Approaches to assessment and treatment of children with DCD: an evaluative review. Journal of Child Psychology \& Psychiatry, 46, 806-823.

Wilson, P. \& McKenzie, B. (1998) Information Processing Deficits Associated with Developmental Coordination Disorder: A Meta-analysis of Research Findings. Journal of Child Psychology \& Psychiatry, 39, 829-840.

Wright, H.C. \& Sugden, D.A.(1996) The nature of Developmental Coordination Disorder: Inter- and Intra-group differences. Adapted Physical Activity Quarterly, 13, 357-371.

\section{Figure Legends}

Figure 1 Selection and intervention stages for the pilot study.

Figure 2 Mean outcome scores for each Group at each time point (A) BOT-2 percentile;

(B) CSQ ability; (C) CSQ Satisfaction. 
Table 1: Mean (SD) and range for participant characteristics for each group, and baseline assessment measures. Number of males (females) also shown.

\begin{tabular}{lccc}
\hline & Group.A $(\mathrm{n}=10)$ & Group.B $(\mathrm{n}=8)$ & Statistic \\
\hline Gender M (F) & $8(2)$ & $6(2)$ & $\chi^{2}(1) .06, \mathrm{p}=.80$ \\
Age (years) & $8.53(1.15)$ & $9.53(1.42)$ & $\mathrm{t}(16)-1.65, \mathrm{p}=.12$ \\
& $7.08-10.67$ & $7.17-10.92$ & \\
DCDQ & $42.0(8.9)$ & $41.67(8.94)$ & $\mathrm{t}(13) .07, \mathrm{p}=.95$ \\
(max=75) & $32-57$ & $29-53$ & \\
BOT-2 & $7.9(5.53)$ & $11.43(10.44)$ & $\mathrm{t}(15)-.91, \mathrm{p}=.38$ \\
(percentile) & $2-16$ & $4-31$ & \\
CSQ: Ability & $27.5(6.75)$ & $30(7.93)$ & $\mathrm{t}(16)-.72, \mathrm{p}=.48$ \\
(max=45) & $17-36$ & $21-43$ & \\
CSQ: Satisfaction & $28.9(6.24)$ & $30.75(7.4)$ & $\mathrm{t}(16)-.58, \mathrm{p}=.57$ \\
(max=45) & $19-40$ & $22-45$ & \\
SDQ & $17.38(6.28)$ & $14.17(9.91)$ & $\mathrm{t}(12) .74, \mathrm{p}=.47$ \\
(max=40) & $7-26-$ & $7-34$ & \\
\hline
\end{tabular}


Table 2: Individual participant data on each measure at baseline, end of Phase.1 and end of Phase.2.

\begin{tabular}{|c|c|c|c|c|c|c|c|c|c|c|c|c|c|c|c|}
\hline \multirow[t]{2}{*}{ Group } & \multirow[t]{2}{*}{ Child } & \multirow[t]{2}{*}{ Gender } & \multirow{2}{*}{$\begin{array}{c}\text { Age } \\
\text { (Y.M) }\end{array}$} & \multirow[t]{2}{*}{ DCDQ } & \multicolumn{3}{|c|}{ BOT-2 (percentile) } & \multicolumn{3}{|c|}{ CSQ (Ability) } & \multicolumn{3}{|c|}{ CSQ (Satisfaction) } & \multicolumn{2}{|c|}{ SDQ } \\
\hline & & & & & Baseline & Phase.1 & Phase. 2 & Baseline & Phase.1 & Phase. 2 & Baseline & Phase.1 & Phase. 2 & Baseline & Phase.1 \\
\hline A & 1 & $\mathrm{M}$ & 7,01 & 32 & 14 & 16 & 8 & 21 & $38^{* *}$ & 39 & 23 & $33^{* *}$ & 33 & 20 & 14 \\
\hline A & 2 & $\mathrm{~F}$ & 7,03 & 33 & 2 & 3 & 1 & 22 & $38^{* *}$ & 35 & 24 & $40^{* *}$ & 35 & & 6 \\
\hline A & 3 & $\mathrm{M}$ & 7,04 & 39 & 16 & 24 & 12 & 17 & $45^{* *}$ & 43 & 19 & $44^{* *}$ & 45 & 23 & \\
\hline A & 4 & M & 9.05 & 39 & 12 & $27^{\neq}$ & 10 & 35 & $45^{* *}$ & 45 & 31 & $41^{* *}$ & $44^{\neq}$ & 26 & \\
\hline A & 5 & M & 8,06 & & 7 & $54^{*}$ & 8 & 24 & $37^{* *}$ & 37 & 27 & $36^{* *}$ & $41^{*}$ & 14 & \\
\hline A & 6 & M & 7,11 & 39 & 4 & 35 & 10 & 36 & 37 & 39 & 40 & 39 & 36 & 12 & \\
\hline A & 7 & M & 8,09 & 56 & 5 & $14^{\neq}$ & 8 & 30 & 31 & $41^{*}$ & 31 & 33 & $44^{* *}$ & 21 & 16 \\
\hline A & 8 & M & 9,02 & 40 & 3 & $14^{\neq}$ & 12 & 36 & 34 & 34 & 36 & 37 & 36 & 7 & 7 \\
\hline A & 9 & $\mathrm{~F}$ & 9,01 & 43 & 2 & $10^{\neq}$ & 7 & 25 & $28^{*}$ & 22 & 27 & 27 & $29^{\neq}$ & & \\
\hline A & 10 & M & 10,07 & 57 & 14 & 24 & 24 & 29 & $37^{* *}$ & $42^{*}$ & 31 & $39 * *$ & $42^{\neq}$ & 16 & 11 \\
\hline B & 11 & M & 7,02 & 29 & 31 & 12 & $21^{\neq}$ & 23 & $28 *$ & 38 & 24 & $30^{*}$ & $45^{* *}$ & & \\
\hline B & 12 & M & 10,11 & 44 & 4 & 6 & $24^{*}$ & 21 & $23^{\neq}$ & $28^{*}$ & 22 & 20 & $29^{* *}$ & 13 & \\
\hline B & 13 & M & 10,03 & & & 18 & 18 & 43 & 43 & 43 & 45 & 43 & 42 & & \\
\hline B & 14 & M & 10,07 & 33 & 6 & 8 & 16 & 21 & $31^{* *}$ & 34 & 25 & $29 *$ & $33^{*}$ & 34 & \\
\hline B & 15 & $\mathrm{~F}$ & 10,04 & 53 & 8 & $27^{*}$ & 10 & 31 & 32 & $38^{* *}$ & 30 & 32 & $39^{* *}$ & 9 & 13 \\
\hline B & 16 & M & 8,02 & & 21 & 6 & $24^{\neq}$ & 37 & 38 & 40 & 35 & $42^{* *}$ & 36 & 8 & 9 \\
\hline B & 17 & $\mathrm{~F}$ & 10,05 & 46 & 5 & 10 & $18^{\neq}$ & 33 & 33 & 33 & 33 & $37^{*}$ & 33 & 12 & \\
\hline B & 18 & M & 8,04 & 45 & 5 & 5 & $14^{\neq}$ & 31 & $36^{*}$ & 33 & 32 & $35^{\neq}$ & 33 & 9 & 9 \\
\hline
\end{tabular}

A: Wii Fit intervention, then Jump Ahead; B: Jump Ahead, then Wii Fit

$* *=\geq 2$ Least Degree of Difference; $*=\geq 1$ Least Degree of Difference; ${ }^{*} \geq 1 / 2$ Least Degree of Difference

1: No SDQ data were available at the end of Phase.2. 
Table 3: Mean (SD) and range for BOT-2 subscores for Group.A (n=10) and Group.B (n=8), at baseline, end of Phase.1 and end of Phase.2 assessments.

\begin{tabular}{lcccccc}
\hline & \multicolumn{2}{c}{ Baseline } & \multicolumn{2}{c}{ End Phase.1 } & \multicolumn{2}{c}{ End Phase.2 ${ }^{\mathrm{b}}$} \\
\cline { 2 - 7 } & Group.A & Group.B & Group.A & Group.B & Group.A & Group.B \\
\hline Fine motor precision & $9.2(1.95)$ & $10.4(3.26)$ & $10.3(2.39)$ & $10.0(2.51)$ & $10.2(2.92)$ & $12.25(2.38)$ \\
& $6-12$ & $5-14$ & $7-14$ & $7-14$ & $5-14$ & $7-14$ \\
Fine motor integration & $7.5(2.17)$ & $9.0(0.82)$ & $8.9(2.45)$ & $8.25(1.83)$ & $7.6(2.06)$ & $9.25(1.16)$ \\
& $5-9$ & $8-10$ & $5-10$ & $5-10$ & $4-10$ & $7-10$ \\
Manual dexterity & $4.3(1.23)$ & $4.14(1.07)$ & $5.3(1.04)$ & $4.5(1.31)$ & $5.3(1.39)$ & $5.5(0.76)$ \\
Bilateral coordination & $3-6$ & $8-10$ & $4-7$ & $2-6$ & $3-7$ & $4-6$ \\
& $4.6(1.83)$ & $6.29(0.76)$ & $6.4(0.91)$ & $5.5(0.93)$ & $5.8(1.46)$ & $7.38(1.06)$ \\
Balance & $3-7$ & $5-7$ & $5-7$ & $4-7$ & $3-7$ & $6-9$ \\
Running speed \& agility & $5.9(2.84)$ & $7.57(0.79)$ & $7.8(2.91)$ & $6.88(1.46)$ & $7.5(3.28)$ & $8(0)$ \\
& $3-8$ & $6-8$ & $7-8$ & $4-8$ & $5-8$ & 8 \\
Upper limb coordination & $1.2(4.12)$ & $1.57(0.53)$ & $2.3(3.86)$ & $1.5(0.53)$ & $1.3(3.88)$ & $1.75(0.46)$ \\
& $0-3$ & $1-2$ & $1-4$ & $1-2$ & $0-2$ & $1-2$ \\
Strength & $7.8(2.99)$ & $6.71(1.5)$ & $8.9(2.43)$ & $9.13(1.89)$ & $8.2(2.27)$ & $10(2)$ \\
& $2-12$ & $4-8$ & $3-12$ & $7-12$ & $6-12$ & $7-12$ \\
\hline
\end{tabular}

a End of Wii intervention for Group.A; ${ }^{b}$ End of Wii intervention for Group.B 
Table 4: Confidence intervals (CI) for BOT-2 and CSQ total scores for each Group.At baseline, end of Phase.1 and end of Phase.2 assessments.

\begin{tabular}{lcccccc}
\hline & \multicolumn{2}{c}{ Baseline } & \multicolumn{2}{c}{ End Phase.1 a } & \multicolumn{2}{c}{ End Phase.2 ${ }^{\mathrm{b}}$} \\
\cline { 2 - 7 } & Group.A & Group.B & Group.A & Group.B & Group.A & Group.B \\
\hline BOT-2 percentile & $3.95-11.85$ & $1.78-21.08$ & $11.72-32.48$ & $3.49-17.65$ & $5.83-14.17$ & $13.3-22.99$ \\
CSQ Ability & $22.67-32.33$ & $22.21-34.08$ & $33.18-40.82$ & $26.95-36.19$ & $33.04-42.36$ & $31.07-38.65$ \\
CSQ Satisfaction & $24.43-33.37$ & $24.07-33.36$ & $33.4-40.4$ & $25.7-38.58$ & $34.61-42.39$ & $30.6-40.26$ \\
\hline
\end{tabular}

a End of Wii intervention for Group.A; ${ }^{b}$ End of Wii intervention for Group.B 


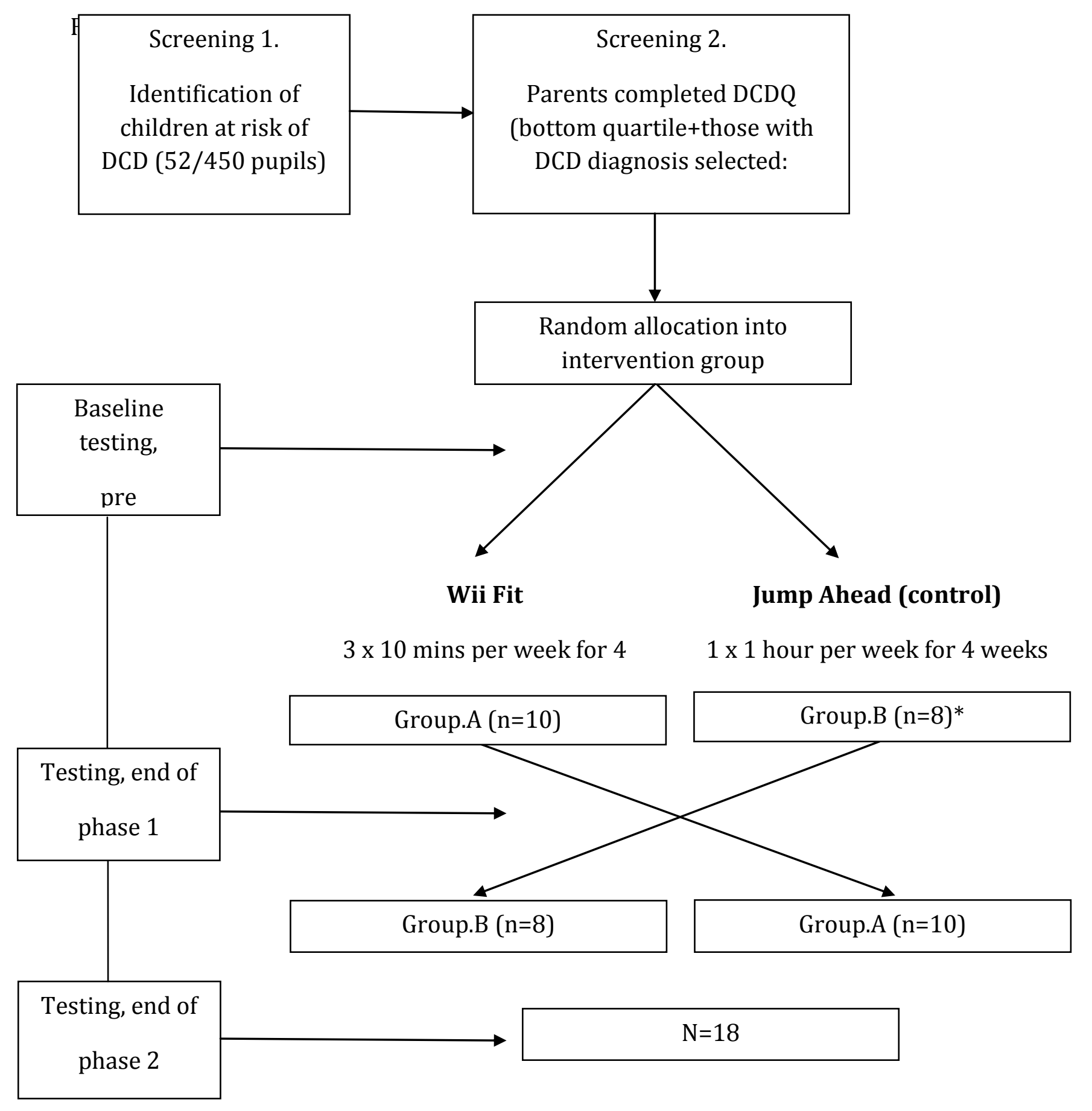
* One child who participated in Group.B was ill at baseline assessment and was therefore not included in analyses. A further child in Group.B was withdrawn from the study in the first week due to parental concerns over potential stigmatization.


Figure 2

Figure 2A

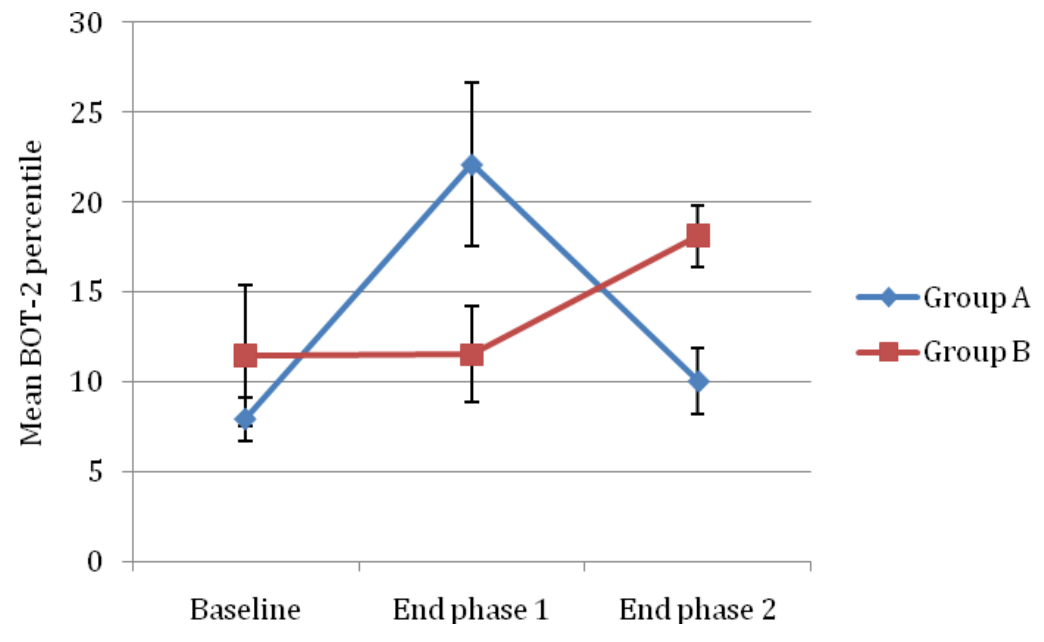

Figure 2B

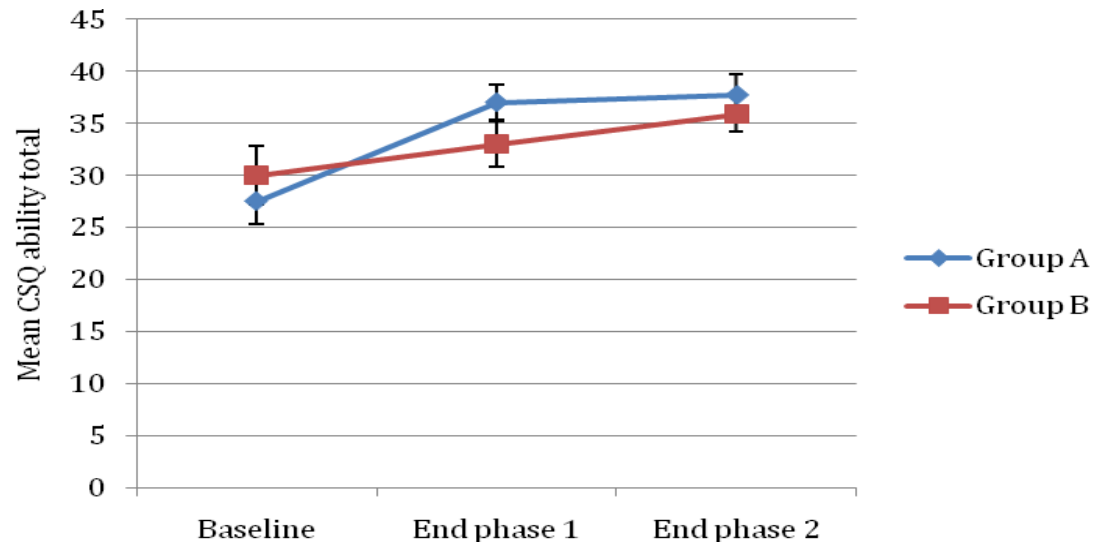

\section{Figure 2C}

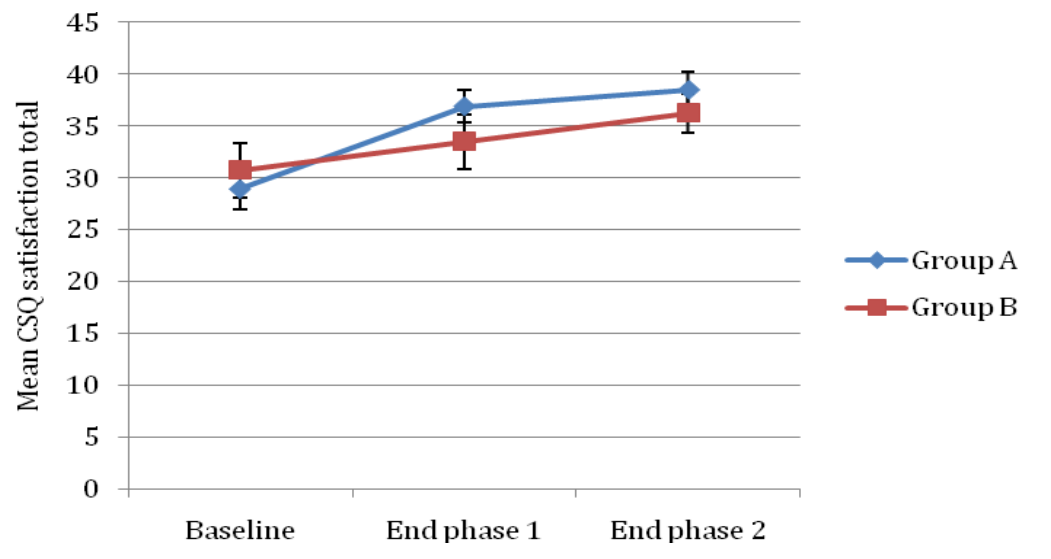

